\title{
Necropsy study of the association between sudden cardiac death, cardiac isoenzymes and contraction band necrosis
}

\author{
D J Hopster, C M Milroy, J Burns, N B Roberts
}

\begin{abstract}
Aims-To assess whether a quantitative analysis of myocardial contraction bands could aid the postmortem identification of early myocardial infarction, especially if used in conjunction with cardiac isoenzyme activities.

Methods-Sixty four coroner's necropsies were grouped by gross and histological findings into 26 cases of definite non-cardiac death, 12 cases of definite myocardial infarction and 26 cases in which there was occlusive coronary artery atheroma, but no demonstrable evidence of infarction. Using multiple sections of left ventricular myocardium stained with Heidenhain's iron haematoxylin, the number of myocardial cells containing contraction bands per unit area was quantified. The results were analysed statistically using logistic regression, and were then compared and combined with results from the statistical analysis of postmortem cardiac isoenzymes that had recently been undertaken on the same cases.
\end{abstract}

Results-The number of cells containing contraction bands per unit area was higher in cases of definite myocardial infarction compared with those of non-cardiac deaths. In addition, cases of occlusive coronary artery atheroma only could be identified, indicating the presence of early myocardial infarction. The accuracy of this identification could be improved by combining these results with the results from the statistical analysis of postmortem cardiac isoenzymes.

Conclusion-The quantitative assessment of myocardial contraction band necrosis can provide useful additional information in cases of sudden death, where myocardial infarction is suspected but not identified on routine histological staining. The value of the information obtained is increased when used in conjunction with the postmortem measurement of cardiac isoenzyme activities. ( $($ Clin Pathol 1996;49:403-406)

Department of Forensic Pathology, University of Sheffield C M Milroy

Correspondence to: Dr J Burns, Sub-Department of Forensic Pathology, Rathology,
Royal Liverpool University

PO Box 147

Liverpool L69 3BX.

Accepted for publication

16 January 1996
Keywords: contraction band necrosis, cardiac isoenzymes, sudden death, myocardial infarction, postmortem.

The identification of early myocardial infarction is a common problem in necropsy pathology, as sudden cardiac death is the most common finding in postmortem examinations carried out for the coroner. ${ }^{1}$ In such cases, however, occlusive coronary artery atheroma is often the only finding. This is because the time interval involved is too short to allow the development of identifiable infarction. Although many and various methods have been described to identify early infarction, at present there is no one single technique in regular use that can recognise these early signs of cell injury and death. Recently, however, three of us have been able to demonstrate that the measurement of cardiac isoenzyme activities can aid the identification of early myocardial infarction. ${ }^{2}$ The present study was undertaken to assess whether a quantitative analysis of myocardial contraction bands could improve the accuracy of such a diagnosis, when used in conjunction with cardiac isoenzyme activities.

Contraction band necrosis, also known as myofibrillar degeneration ${ }^{3}$ and coagulative myocytolysis, ${ }^{4}$ is a type of cell death that is identifiable as early as two minutes after irreversible cell injury has occurred. ${ }^{5}$ The lesion is produced by a disruption of the linear arrangement of myofibrils via hypercontraction, leaving dense aggregates of both thick and thin filaments that are separated by clearer areas now devoid of myofibrils. ${ }^{6}$ These aggregates are seen as faint transverse eosinophilic bands on routine staining with haematoxylin and eosin, but are much easier to identify (fig 1) using special histochemical stains, such as Masson's or Gomori's trichrome, ${ }^{7}$ Luxol fast blue, ${ }^{8}$ Mallory's phosphotungstic acid haematoxylin, ${ }^{9}$ and Heidenhain's iron haematoxylin. Other features of this process include an interstitial mononuclear cell proliferation, relative sparing of stroma, vessels and nerves, a lack of a neutrophilic infiltrate, and the frequent appearance of a granularity within the muscle cells. This latter phenomenon corresponds to the mineralisation of translocated mitochondria at an ultrastructural level. Electron microscopy also demonstrates myofilaments out of register, aggregating to produce contraction bands at a microscopic level. With time, there is loss of nuclear structure and degenerative cytoplasmic changes, and healing eventually occurs via phagocytosis of debris and subsequent fibrosis. ${ }^{10}$

\section{Methods}

Necropsies carried out for Her Majesty's coroner were grouped into non-cardiac deaths, deaths from definite myocardial infarction and deaths with occlusive coronary atheroma but 


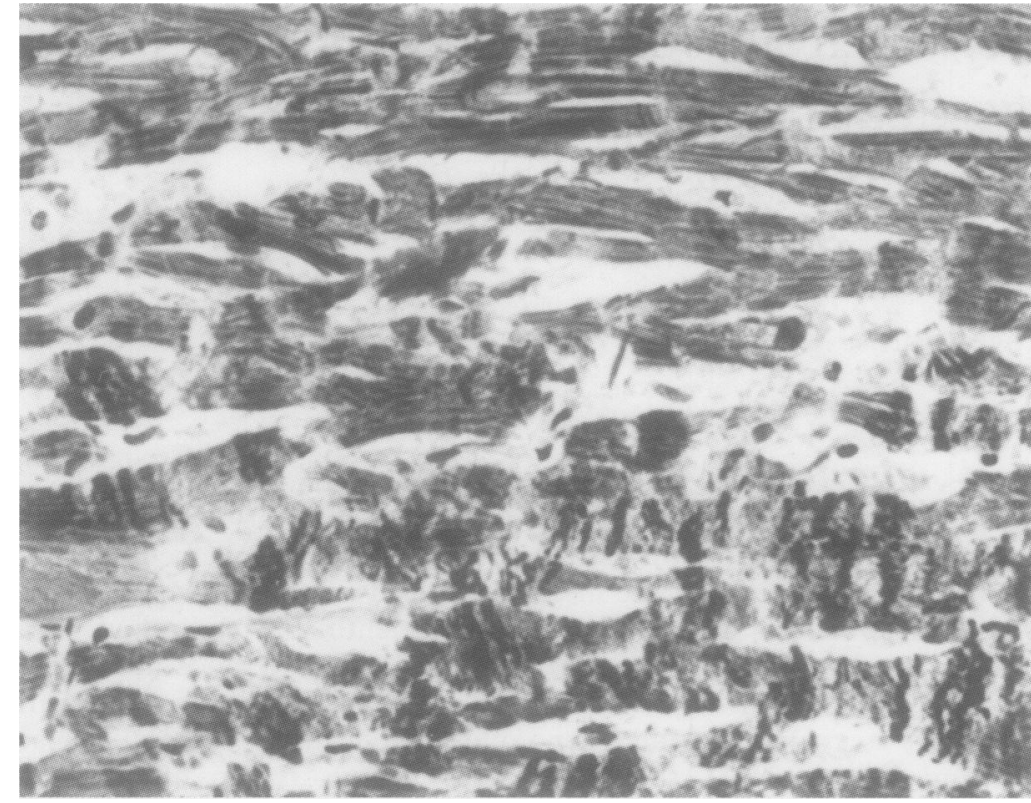

Figure 1 Section of myocardium showing numerous transverse contraction bands, most pronounced in the upper half of the figure (Heidenhain's iron haematoxylin).

Table 1 Non-cardiac deaths $(n=26)$

\begin{tabular}{lr}
\hline Bands $/ \mathrm{mm}^{2}$ & $P M I$ \\
\hline $0 \cdot 02$ & 26 \\
0.02 & 30 \\
$0 \cdot 03$ & 22 \\
$0 \cdot 14$ & 6 \\
$0 \cdot 03$ & 26 \\
$0 \cdot 06$ & 15 \\
$0 \cdot 07$ & 16 \\
$0 \cdot 10$ & 20 \\
$0 \cdot 04$ & 70 \\
$0 \cdot 15$ & 21 \\
0.05 & 62 \\
$1 \cdot 25$ & 3 \\
$0 \cdot 42$ & 10 \\
$0 \cdot 25$ & 21 \\
$0 \cdot 27$ & 23 \\
$2 \cdot 01$ & 4 \\
$2 \cdot 22$ & 4 \\
$0 \cdot 36$ & 26 \\
$2 \cdot 68$ & 4 \\
$0 \cdot 39$ & 25 \\
$0 \cdot 20$ & 50 \\
$0 \cdot 18$ & 56 \\
$0 \cdot 16$ & 66 \\
$0 \cdot 31$ & 56 \\
$0 \cdot 54$ & 51 \\
$0 \cdot 77$ & 37 \\
\hline
\end{tabular}

Table 2 Possible infarct $(n=26)$

\begin{tabular}{lr}
\hline Bands $/ \mathrm{mm}^{2}$ & $P M I$ \\
\hline $0 \cdot 02$ & 8 \\
$0 \cdot 08$ & 3 \\
$0 \cdot 03$ & 15 \\
$0 \cdot 04$ & 14 \\
$0 \cdot 03$ & 24 \\
$0 \cdot 15$ & 13 \\
$0 \cdot 12$ & 20 \\
$0 \cdot 12$ & 21 \\
$0 \cdot 12$ & 24 \\
$0 \cdot 13$ & 36 \\
$0 \cdot 17$ & 40 \\
$0 \cdot 52$ & 14 \\
$0 \cdot 12$ & 61 \\
0.92 & 10 \\
$4 \cdot 46$ & 3 \\
$4 \cdot 84$ & 3 \\
1.20 & 14 \\
$0 \cdot 85$ & 24 \\
$5 \cdot 97$ & 5 \\
$1 \cdot 19$ & 26 \\
$4 \cdot 73$ & 11 \\
$0 \cdot 85$ & 69 \\
$3 \cdot 49$ & 24 \\
$5 \cdot 50$ & 16 \\
$7 \cdot 26$ & 15 \\
$2 \cdot 82$ & 39 \\
\hline
\end{tabular}

with no definite macroscopic evidence of infarction. Multiple blocks of paraffin wax embedded left ventricular myocardium were then stained with haematoxylin and eosin and examined to identify or exclude histological evidence of infarction. At necropsy, blood from the right atrium (into which the coronary sinus drains), blood from a peripheral vein and pericardial fluid were collected. The following cardiac isoenzymes were measured in each case: aspartate aminotransferase; hydroxybutarate dehydrogenase; total creatine phosphokinase $(\mathrm{CPK})$; and the creatine phosphokinase isoenzymes CPK-MM, CPK-MB and CPK-BB. The creatine phosphokinase isoenzymes were measured by quantitative electrophoresis and the enzyme activity by a standard procedure using a centrifugal analyser. The total CPK for each sample was measured, then a second sample with activity up to $1000 \mathrm{IU} / 1$ was used for electrophoresis. Samples with activity greater than $1000 \mathrm{IU} / 1$ were diluted accordingly using isotonic saline. The results of this biochemical analysis have been published previously in a study from our departments. ${ }^{2}$

For the purposes of this investigation, a section of each block was stained with $\mathrm{Hei}-$ denhain's iron haematoxylin and the number of cells $/ \mathrm{mm}^{2}$ containing contraction bands (bands $/ \mathrm{mm}^{2}$ ) was quantified, using a method that has been described previously, ${ }_{11}^{11}$ where the total number of cells containing contraction bands was counted in each section, using a Leitz dialux microscope with a $40 \times$ objective lens. The area of each of these sections was then measured using a Kontron mop-30 image analyser system connected to a digitising tablet. All of these results were obtained without prior knowledge of the group to which each case had been assigned. The reproducibility of these results was assessed by measuring the intraobserver error, which was found to be less than $5 \%$, and was established by taking 10 sections at random, and recounting the number of cells containing contraction bands and remeasuring the area. In total 64 cases were collected for which the full biochemical data were included and the number of cells $/ \mathrm{mm}^{2}$ containing contraction bands could be quantified. Additionally, in all cases the postmortem examination interval (PMI) was known, which was the time in hours between death and necropsy.

\section{Results}

The 64 cases had already been classified into three groups from the results of the necropsy, in combination with the histological evidence. There were 26 cases of non-cardiac death, 12 cases of definite myocardial infarction, and 26 cases of occlusive coronary artery atheroma without evidence of infarction - that is, possible myocardial infarction. The section with the highest number of cells $/ \mathrm{mm}^{2}$ containing contraction bands was selected from the multiple sections examined in each of the 64 cases, and was used for statistical analysis. The number of cells $/ \mathrm{mm}^{2}$ containing contraction bands varied from 0.02 to 12.25 with a mean of 1.87 , and decreased with increases in the PMI, which itself varied from three to 70 hours, with a mean of 25 hours.

The results were analysed statistically using logistic regression and discriminant analysis, ${ }^{12}$ both of which gave similar results. Logistic regression, however, is the preferred technique, as it does not assume multivariate normality of the predictor variables and leads to a direct estimate of the probability of death from a cardiac cause without resorting to Bayes' theorem $^{13-15}$ which permits the combination of many individual test results to give a final odds ratio. It predicts a future event based upon associated events of the past and although the principle is simple, the implementation of the theorem requires much tedious calculation. Using logistic regression, $\mathrm{L}=\operatorname{logit}(\mathrm{p})=\ln (\mathrm{p} /$ $[1-\mathrm{p}])$, where $\mathrm{p}=\exp (1)+\exp (1) ; \mathrm{p}$ is the estimated probability of the death being due to myocardial infarction, and a "predicted positive" result is indicated by values of $p>0.5$. Tables 1, 2 and 3 contain the relevant data collected in this investigation and also show the resulting $p$ values from the biochemical analysis of the same cases. When the number of cells $/ \mathrm{mm}^{2}$ containing contraction bands and the PMI were combined, the results in table 4 were obtained. In this model, $92 \%(24 / 26)$ of the non-cardiac deaths and $67 \%$ (eight of 12 ) of the deaths due to myocardial infarction were correctly classified. In addition, $27 \%$ (seven of 26) of the cases of possible myocardial infarction could be reclassified as cases of myocardial infarction.

The biochemical data had also been analysed using logistic regression, and the best model was found to be a combination of total CPK in the right atrial blood, percentage of isoenzyme $\mathrm{MB}$ in the peripheral venous blood, percentage of isoenzyme MB in the pericardial fluid, percentage of isoenzyme $M M$ in the pericardial fluid, and the PMI. The results are shown in table 5. Using this model, $92 \%$ (24/ 


\begin{tabular}{ll}
$\begin{array}{l}\text { Table 3 Definite } \\
\text { infarction }(n=12)\end{array}$ \\
\hline Bands/mm ${ }^{2}$ & $P M I$ \\
\hline 0.03 & 45 \\
0.07 & 27 \\
0.51 & 16 \\
0.46 & 26 \\
$12 \cdot 25$ & 10 \\
6.37 & 19 \\
3.43 & 36 \\
10.84 & 16 \\
10.74 & 18 \\
9.42 & 21 \\
10.33 & 20 \\
5.41 & 38 \\
\hline
\end{tabular}

Table 4 Model using PMI and number of cells $/ \mathrm{mm}^{2}$ containing contraction bands

\begin{tabular}{lll}
\hline Classification & $\begin{array}{l}\text { Predicted } \\
\text { non-infarct }\end{array}$ & $\begin{array}{l}\text { Predicted } \\
\text { infarct }\end{array}$ \\
\hline Non-cardiac & 24 & 2 \\
Infarct & 4 & 8 \\
Possible infarct & 19 & 7 \\
\hline
\end{tabular}

$\operatorname{Logit}(\mathrm{p})=-3 \cdot 503+2 \cdot 425 \log (\mathrm{PMI})+2 \cdot 283 \log \left(\right.$ bands $\left./ \mathrm{mm}^{2}\right)$.

Table 5 Model using PMI, total CPK and percentage isoenzymes

\begin{tabular}{llc}
\hline Classification & $\begin{array}{l}\text { Predicted } \\
\text { non-infarct }\end{array}$ & $\begin{array}{l}\text { Predicted } \\
\text { infarct }\end{array}$ \\
\hline Non-cardiac & 24 & 2 \\
Infarct & 8 & 4 \\
Possible infarct & 16 & 10 \\
\hline
\end{tabular}

$\operatorname{Logit}(\mathrm{p})=5 \cdot 529-0.653 \log (\mathrm{PMI})$

$+1.003 \log$ (total right atrial CPK)

-0.187 (\%isoenzyme MB in peripheral venous blood)

-0.162 (\%isoenzyme MB in pericardial fluid)

-0.078 (\%isoenzyme MM in pericardial fluid)

Table 6 Model combining results from tables 4 and 5

\begin{tabular}{lll}
\hline Classification & $\begin{array}{l}\text { Predicted } \\
\text { non-infarct }\end{array}$ & $\begin{array}{l}\text { Predicted } \\
\text { infarct }\end{array}$ \\
\hline Non-cardiac & 22 & 4 \\
Infarct & 2 & 10 \\
Possible infarct & 11 & 15 \\
\hline
\end{tabular}

26) of the non-cardiac deaths and 33\% (four of 12) of the deaths due to myocardial infarction were correctly classified. In addition, 38\% (10/ 26) of the cases of possible myocardial infarction could be reclassified as cases of myocardial infarction.

It is possible to combine the results of the contraction band quantification and the biochemical analysis, as the same cases have been used in each, and the same statistical analyses applied. In doing so, $\mathrm{p}>0.5$ in either study (or both studies) has been used to indicate a "predicted positive" result. The results of this combination are shown in table 6 . In this model, $85 \%(22 / 26)$ of the non-cardiac deaths and $83 \%(10 / 12)$ of the deaths due to myocardial infarction were correctly identified. In addition, $58 \%(15 / 26)$ of the cases of possible myocardial infarction could be reclassified as cases of myocardial infarction.

\section{Discussion}

Contraction band necrosis has been known about for several decades, although various synonymous terms have been in use. In 1904, Smith noted that focal myocytolysis occurred at the border of myocardial infarcts ${ }^{16}$ and in 1906 Pearce observed the occurrence of hyaline necrosis in rabbit myocardium after multiple injections of adrenaline. ${ }^{17}$ The actual term "contraction bands" was first introduced by Caulfield and Klionsky in 1959. ${ }^{18}$ However, they were not referring to contraction band necrosis proper, but to the thickening of $\mathrm{Z}$ bands that they observed in rabbit myocardium after 20 minutes of coronary artery ligation. It was Jennings et al who first recognised that the presence of contraction bands indicated a specific type of necrosis. ${ }^{19-21}$ In their studies, and in subsequent experiments by others, contraction band necrosis was produced by reperfusion following temporary ischaemia. ${ }^{22-25}$ It also occurred at the boundary of an area of coagulative necrosis following permanent ischaemia. Other studies have shown that increased catecholamine concentrations, either exogenous or endogenous, can produce contraction band necrosis, ${ }^{1026-28}$ which has consequently been reported in the following: administration of polymxyin, neomycin, plasmocid, streptokinase, trypsin, ficin, papain, cobalt, and corticoids; potassium and magnesium deficiency; hypothermia; oxygen toxicity; electric shock; haemorrhagic shock; intra-cranial haemorrhage; near drowning; cocaine abuse; pheochromocytomas; and severe emotional stress. ${ }^{102-31}$ These conditions are not relevant to the current study though, as the majority can be excluded from the clinical details alone, and the remainder eliminated by routine postmortem examination, biochemistry and toxicology. Of more importance, however, is the fact that contraction band necrosis can be produced by resuscitation, via both catecholamine administration and defibrillation, ${ }^{32}$ thereby making their quantification unhelpful in such cases. In this study all cases were of sudden death without resuscitation. However, even in those cases where resuscitation has been attempted, there is likely to be other evidence of myocardial infarction, such as an electrocardiogram.

In 1954, Schlesinger and Reimer identified the presence of contraction band necrosis in 51 of 80 hearts showing recent coagulative necrosis, compared with 45 of 278 hearts showing previous fibrosis and five of 213 normal hearts. ${ }^{33}$ In addition, the present study showed that the extent of the contraction band necrosis was greatest in those hearts where coagulation necrosis was also identified. Bouchardy and Majno, in 1973, seem to have been the first to suggest that contraction band necrosis represented a discrete but important sign of cellular disease in early infarcts and that consequently it could be a useful adjunct in the diagnosis of early myocardial ischaemia. ${ }^{34}$ In 1975, Baroldi reviewed the functional significance of different types of myocardial necrosis. ${ }^{35}$ In 100 cases of definite myocardial infarction, contraction band necrosis was documented in a total of $96 \%$ of cases, and in 200 cases of sudden death with obstructive coronary artery atheroma, but no demonstrable infarction, contraction band necrosis was the only lesion in $67 \%$ of cases. In $16 \%$ of these cases, coagulative necrosis was also identified, $76 \%$ of which also contained contraction band necrosis. Later, in 1975, Reichenbach and Moss published a study of myocardial cell necrosis and sudden death. ${ }^{36}$ of 50 cases of sudden death, contraction band necrosis was found in $88 \%$. Furthermore, 16 of these cases showed coagulative necrosis. However, severe coronary artery atheroma was rare. In 1979, Baroldi et al published another postmortem study of sudden coronary death. ${ }^{4}$ Of 208 cases of sudden death, contraction band necrosis was the unique lesion in $72 \%$ of cases and was seen 
in a total of $86 \%$ of cases, when those with coagulative necrosis were included. They concluded that contraction band necrosis may be either the first sign of myocardial infarction or a primary sympathetic disorder linked with ventricular fibrillation. In 1970, Wu et al published a quantitative analysis of contraction band necrosis and infarction in cases with near normal arteries. ${ }^{37}$ They found that in cases of infarction, an average area of $86 \%$ was occupied by contraction band necrosis.

The results of our study show that eight of 12 cases of definite infarction contained contraction band necrosis. Although in four cases contraction band necrosis was not identified, this is not a diagnostic problem, as routine histological examination had revealed the presence of coagulative necrosis. Twenty four of 26 cases of non-cardiac death were also identified, confirming that contraction band necrosis is not an artefactual occurrence. In the two non-cardiac cases that showed significant contraction band necrosis, identifiable factors were present which could account for its presence. Of the possible infarct group, seven of 26 cases contained significant contraction band necrosis, which approaches the diagnostic accuracy of isoenzyme analysis. The best results, however, come from using a combination of contraction band necrosis quantification and biochemical analysis, when 15 of 26 test cases can be identified as cases of infarction, whilst still maintaining good identification of both definite infarction and non-cardiac deaths. Although not all cases of early myocardial infarction can be predicted using contraction band necrosis quantification and isoenzyme analysis, any additional information is always useful in controversial cases. It is also noteworthy that most failures were false negatives rather than false positives, indicating that a positive result can be viewed with some confidence.

In conclusion, we would recommend that in cases of sudden unexplained death, when myocardial infarction is suspected but not identified, valuable information can be obtained when cardiac isoenzyme analysis is combined with quantification of contraction band necrosis.

We would like to thank Joan Holtom for her technical assistance and Christopher West for his statistical advice.

1 Knight B. The pathology of sudden death. In: Forensic pathology. London: Edward Arnold, 1991:444-54.

2 Burns J, Milroy CM, Hulewicz B, West CR, Walkley SM Roberts NB. Necropsy study of association between sudden death and cardiac enzymes. $¥$ Clin Pathol 1992;45 217-20.

3 Reichenbach DD, Benditt EP. Myofibrillar degeneration: A response of the myocardial cell to injury. Arch Pathol 1968; 85:189-99.

4 Baroldi G, Falzi G, Mariani F. Sudden coronary death. A post-mortem study in 208 selected cases compared to 97

5 Oehmichen M, Pedal I, Hohmann P. Diagnostic significance of myofibrillar degeneration of cardiocytes in forensic of myofibrillar degeneration of cardiocyte

pathology. Forensic Sci Int 1990;48:163-73.
6 Karch SB, Billingham ME. Myocardial contraction bands revisited. Hum Pathol 1986;17:9-13.

7 Morales AR, Fine G, Taber RE. Cardiac surgery and myocardial necrosis. Arch Pathol 1967;83:71-9.
8 Arnold G, Fischer R. Myocardial "contraction bands" (letter). Hum Pathol 1987;18:99-101.

9 Stahl E. Screening of myocardial contraction bands: A comparison between two histological staining methods. comparison between two histo
Forensic Sci Int 1990;45:151-7.

10 Reichenbach DD, Benditt EP. Catecholamines and cardiomyopathy: The pathogenesis and potential importance of myofibrillar degeneration. Hum Pathol 1970;1:125-50.

11 Adomian GE, Laks MM, Billingham ME. The incidence and significance of contraction bands in endomyocardial biopsies from normal human hearts. Am Heart $\mathcal{f} 1978 ; 95$ : 348-51.

12 Altman DG. Relation between several variables. In: Practical statistics for medical research. London: Chapman Hall, 1991: 351-60.

13 Bayes T. (1764). An essay towards solving a problem in the doctrine of chances. Philosophical Transactions of the Royal Society of London for $1763,53,370-418$. Reprinted Royal Society of London for 1763, 53, 370-418. Reprinted
with Barnard (1958), Pearson and Kendal (1970), 131153.

14 Pearson ES, Kendall MG (eds). Studies in the history of statistics and probability. London: Charles Griffin, 1970.

15 Barnard, G.A. (1958) Thomas Bayes - a biographical note (together with a reprinting of Bayes, 1764). Biometrika 45, 293-315. Reprinted in Pearson and Kendall (1970), 131-153

16 Smith AJ. On the histological behaviour of the cardiac muscle in two examples of organization of myocardial infarct. Univ Pennsylvania Med Bull 1904;17:227-34.

17 Pearce RM. Experimental myocarditis: A study of the histological changes following intravenous injections of adrenalin. $f$ Exp Med 1906;8:400.

18 Caulfield J, Klionsky B. Myocardial ischaemia and early infarction: An electron microscopic study. Am $₹$ Pathol 1959;35:489-523.

19 Sommers HM, Jennings RB. Experimental acute myocardial infarction. Histologic and histochemical studies of early myocardial infarcts induced by temporary or permanen occlusion of a coronary artery. Lab Invest 1964;13:1491503.

20 Herdson PB, Sommers HM, Jennings RB. A comparative study of the fine structure of normal and ischaemic dog myocardium with special reference to early changes following temporary occlusion of a coronary artery. $\mathrm{Am} \mathcal{f}$ Pathol 1965;46:367-86.

21 Kloner RA, Ganote CE, Whalen DA, Jennings RB. Effect of a transient period of ischaemia on myocardial cells. II. Fine structure during the first few minutes of reflow. $\mathrm{Am}$ F Pathol 1974;74:399-413.

22 Ganote CE, Worstell J, Iannotti JP, Kaltenbach JP. Cellular swelling and irreversible myocardial injury. Effects of polyethylene glycol and mannitol in perfused rat hearts. Am $\mathcal{f}$ Pathol 1977;88:95-109.

23 Hutchins GM, Silverman KJ. Pathology of the stone heart syndrome. Massive myocardial contraction band necrosis and widely patent coronary arteries. Am 7 Pathol 1979 95:745-52.

24 Miyazaki S, Fujiwara H, Onodera T, Kihara Y, Matsuda $\mathrm{M}, \mathrm{Wu}$ DJ, et al. Quantitative analysis of contraction band and coagulation necrosis after ischaemia and reperfusion in the porcine heart. Circulation 1987;75:1074-82.

25 Matsuda M, Fujiwara H, Onodera T, Tanaka M, Wu DJ, Fujiwara $\mathrm{T}$, et al. Quantitative analysis of infarct size, Fujiwara $\mathrm{T}$, et al. Quantitative analysis of infarct size, contraction band necrosis, and coagulation necrosis in
human autopsied hearts with acute myocardial infarction human autopsied hearts with acute myocardial infarction after treatment with selective

26 Szakacs JE, Cannon A. 1-Norepinephrine myocarditis. $A m$ f Clin Pathol 1958;30:425-34.

27 Szakacs JE, Dimmette RM, Cowart EC. Pathologic implication of the catecholamines, epinephrine and norepinephrine. US Armed Forces Med $\mathcal{f} 1959 ; 10: 908-25$.

28 Csapo Z, Dusek J, Rona G. Early alterations of the cardiac muscle cells in isoproterenol-induced necrosis. Arch Pathol muscle cells in is

29 Lunt DWR, Rose AG. Pathology of the human heart in drowning. Arch Pathol Lab Med 1987;111:939-42.

30 Tazelaar HD, Karch SB, Stephens BG, Billingham ME Cocaine and the heart. Hum Pathol 1987;18:195-9.

31 Cebelin MS, Hirsch CS. Human stress cardiomyopathy. Myocardial lesions in victims of homicidal assaults without internal injuries. Hum Pathol 1980;11:123-32.

32 Karch SB. Resuscitation-induced myocardial necrosis. Catecholamines and defibrillation. Am $\mathcal{f}$ Forensic Med Pathol 1987;8:3-8.

33 Schlesinger MJ, Reiner L. Focal myocytolysis of the heart. Am $\mathcal{F}$ Pathol 1955;31:443-53.

34 Bouchardy B, Majno G. Histopathology of early myocardial infarcts. A new approach. Am $\mathcal{F}$ Pathol 1974;74:301-30.

35 Baroldi G. Different types of myocardial necrosis in coronary heart disease: A pathophysiologic review of their functional significance. Am Heart $\mathcal{F}$ 1975;89:742-52.

36 Reichenbach DD, Moss NS. Myocardial cell necrosis and sudden death in humans. Circulation 1975;51\&52(Suppl III):III 60 s-2s.

37 Wu DJ, Fujiwara H, Matsuda M, Ishida M, Kawamura A Takemura G, et al. Clinicopathological study of myocardial infarction with normal or nearly normal extracardiac coronary arteries. Quantitative analysis of contraction band necrosis, coagulation necrosis, haemorrhage, and infarct size. Heart Vessels 1990;6:55-62. 